\title{
Low use of Modern Family Planning Methods in women suffering from Physical and Psychological abuse by their partiners: Findings from Cross-Sectional Study
}

\author{
Mrimi Simion Baritwa \\ University of Dodoma College of Health and Allied Sciences: The University of Dodoma College of Health Sciences \\ Angelina Alphonce Joho ( $\sim$ johoangeljoho@yahoo.co.uk) \\ University of Dodoma College of Health and Allied Sciences: The University of Dodoma College of Health Sciences \\ https://orcid.org/0000-0003-0142-6081
}

\section{Research}

Keywords: Intimate partner violence, modern family planning, married women, Mara, Tanzania

Posted Date: January 21st, 2021

DOI: https://doi.org/10.21203/rs.3.rs-150736/v1

License: (c) (i) This work is licensed under a Creative Commons Attribution 4.0 International License. Read Full License 


\section{Abstract}

Background: Married women who experience intimate partner violence are less likely to negotiate with their partners on modern family planning use. This study aimed to assess the influence of intimate partner violence on modern family planning use among married women in Mara region.

Methods: A community based analytical cross-sectional study which included 366 married women in Mara from May to July 2019. Seven multistage sampling techniques were employed to select the sample size. A structured questionnaire was used to collect data which were analyzed using SPSS version 20. Binary logistic regression model was applied to determine the predictors of modern family planning use. P-value less than 0.05 was considered significant.

Results: The overall prevalence of intimate partner violence (IPV) was 73\% with $54.1 \%$ physical violence, $36.3 \%$ psychological violence and $25.4 \%$, sexual violence. The prevalence of modern family planning (FP) use was $62 \%$, the most common method practiced by married women was injection (depo Provera) (49.1\%). Factors associated with FP use were physical violence $(A O R=0.32, p=0.0056)$, psychological violence $(A O R=0.22, p=0.0022)$, religious $(A O R=4.6, p=$ $0.0085)$ and availability of preferred FP methods $(A O R=9.27, p<0.0001)$

Conclusion: This study shows a positive association between FP use and IPV. Effective intervention is required to increase modern family plan use and reducing intimate partner violence.

\section{Introduction}

Despite the decrease in the number of maternal deaths for the past decades, nearly 830 women still die every day globally from the avoidable causes related to pregnancy. In Sub-Saharan Africa alone maternal deaths is alarming high with 542 per 100,000 live births reported in 2017 which are contrasted from developed countries with only 12 maternal deaths per 100,000 livebirths (1). In Tanzania, a slight decrease in maternal deaths was observed from 578 per 100,000 live births in 2013 to 556 in $2016(4,13)$.

Several studies have revealed that, modern family planning (FP) use is a key intervention in averting maternal deaths by reducing the pregnancy related complications such as lowering the risks of unsafe abortion, prevent unplanned pregnancies (5-7). Worldwide, the prevalence of FP is $63 \%$ among married women aged 15-49 years which is a slight increase compared to 54\% from 57.4\% reported in 1990 and 2015 respectively globally (8).

Studies indicated that, 1 in 10 married women globally have unmet need for FP but in Africa is 1 in 5 and this made Africa to be the highest region with women who have a unmet need for FP (1). Also in Africa, the overall prevalence of FP was $27.6 \%$ in women of reproductive age (9). Likewise, in Mara region, modern FP use is still low for example in 2016 the prevalence was $29 \%$ which is lower than other regions of Tanzania for example $52 \%, 51 \%$ and $50 \%$ in Lindi, Ruvuma and Mtwara respectively which was reported in the same year. However, is also lower than the National target of $60 \%$ by 2020 (13). In Mara region, about 279 maternal deaths per 100,000 live births were reported from 2015 to 2019 DHIS (2015-20) which probably could be prevented through FP compliance $(10,11)$.

Studies have revealed that, IPV is a factor projecting married women inability to negotiate with male partner on modern FP use and impaired them with physical and psychological in health related decision making (12). Other factors reported were sociodemographic factors: such as age, residence, employment, and level of education $(10,11)$. Despite of the government initiatives to reduce IPV and extend FP services to increase FP use, yet IPV and FP use in Mara region is a health challenge. Due to limited published facts, particularly in Mara region, this study assessed the influence of IPV on modern FP use among married women in Mara region to clear the contradictory gap exist between the independent and dependent variables of this study. 


\section{Materials And Methods}

Study design and setting It was a community - based analytical cross-sectional study conducted in Mara region from April to July 2020. The fertility rate in Mara region is 7.1 (NBS, 2016). For example, from 2018-19, women of reproductive age reported were 454,829 and 515,596 respectively, number of deliveries in 2018-19 were 69,172 and 80,145 respectively. In 2019, the total fertility rate reported in Mara region was 155, which had increased from 152 number of birth per woman in 2018 (DHIS, 2019). Study population This study included all married and cohabiting women aged 15-49 years living in Mara region. Sample size determination The sample size of 366 married women was calculated using the Cochran formula (1977) in which 61\% proportional of modern FP use (6), and a permissible marginal error of $5 \%$ and constant standard normal variation of 1.96 at $95 \%$ confidence interval were applied in calculating the sample size. Sampling technique A number of sampling techniques were applied to select the study settings and study population. Mara region was conveniently selected due to low (29\%) prevalence of modern FP use and highest region with IPV 78\% practice (13). Multistage sampling technique was employed to recruit respondents in Mara region from districts to household level. In each stage of sampling techniques, simple randomly technique was used. Data collection tool and procedure To ensure reliability of the study, a standardized self-administered questionnaire was adopted from Abdulai (2015) to collect FP information and regarding IPV questions, a Revised Conflict Tactics Scale 2 (CTS-2) developed by Straus et al. (1996) with Alpha value of $0.86,0.87$ and 0.79 for physical violence, sexual violence and psychological violence respectively was used. Data collection procedure A structured questionnaire was used to collect the related study information from the eligible respondents during data collection. Based on sensitivity of IPV information which was required from the respondents, research assistants (female nurses) with counselling skills were purposively selected and trained on full package of the data collection tool to generate a common understanding for all, their responsibilities during the data collection from April to July 2020, in the recruited district councils, namely; Butiama, Bunda, Tarime and Serengeti. Measurements of variables Intimate partner violence (physical, sexual and psychological) as independent variable was measured using Conflict Tactics Scale version 2 (CTS-2). All questions used were dichotomous which was coded as 1, if the answer was (Yes) and 0, if the answer was (No). The IPV was defined as 0 if married woman had never experienced any of the three forms of IPV and 1 if she had experienced at least any of either physical, sexual or psychological. Modern family planning use Modern FP use as a dependent variable, was measured into two categories; category $1=$ No, if never used FP and $2=$ Yes, if previously or current use FP. Data processing and analysis Data analysis software called Statistical Package for Social Sciences (SPSS), version 20 for analysis. Descriptive analysis was used to analyze sociodemographic data. Chi - square was used to determine the relationship between the categorical variables. Regression analysis was used to establish association between variables and data were presented using tables and figures. We also ran logistic regression model to determine the association between physical IPV, psychological IPV, sexual IPV and family planning use. Logistic regression model was controlled for the following covariates: participant's age, marital status, highest level of education, residence (urban vs. rural), religion (Roman Catholic or other), occupation, total number of children, years in marriage, monthly income. Both unadjusted and adjusted odds ration were assessed. A two-tailed $p$ value of less than 0.05 was considered significant.

\section{Results}

\section{Sociodemographic characteristics of respondents}

A total of 366 married women included in this study were aged between 15-49 years with mean age 30.26 \pm 7.128 . Majority 272 (74.3\%) residing in rural area. Regarding religion majority of participants 254 (69.4\%) were Christians. More than half of respondents had attained primary school education 197 (53.8\%). Over 191 (52.2\%) of respondents were unemployed. Most of them 166 (45.4\%) reported to have delivered three to four times, of them $137(37.4 \%)$ had 6-10 years of the marriage (Table 1). 
Table 1

Sociodemographic characteristics of the respondents $(N=366)$

\begin{tabular}{|c|c|c|c|}
\hline Variable & Frequency (n) & Percentage (\%) & Mean \pm SD \\
\hline Age (Years) & & & $2.11 \pm 0.815$ \\
\hline $15-24$ & 85 & 23.2 & \\
\hline $25-34$ & 173 & 47.3 & \\
\hline $35-44$ & 90 & 24.6 & \\
\hline $45-49$ & 18 & 4.9 & \\
\hline \multicolumn{4}{|l|}{ Residence } \\
\hline Urban & 94 & 25.7 & \\
\hline Rural & 272 & 74.3 & \\
\hline \multicolumn{4}{|l|}{ Religion } \\
\hline No religion & 61 & 16.7 & \\
\hline Christian & 254 & 69.4 & \\
\hline Muslim & 51 & 13.9 & \\
\hline \multicolumn{4}{|l|}{ Highest education level } \\
\hline Informal education & 60 & 16.4 & \\
\hline Primary education & 197 & 53.8 & \\
\hline Secondary education & 72 & 19.7 & \\
\hline College/university & 37 & 10.1 & \\
\hline \multicolumn{4}{|l|}{ Occupation } \\
\hline Employed & 26 & 7.1 & \\
\hline Self employed & 149 & 40.7 & \\
\hline Unemployed & 191 & 52.2 & \\
\hline Number of parities & & & $2 \pm 0.561$ \\
\hline 0 & 12 & 3.3 & \\
\hline $1-2$ & 101 & 27.6 & \\
\hline $3-4$ & 166 & 45.4 & \\
\hline $5+$ & 87 & 23.8 & \\
\hline Number of living children & & & $2 \pm 0.475$ \\
\hline 0 & 27 & 7.4 & \\
\hline $1-2$ & 133 & 36.3 & \\
\hline $3-4$ & 148 & 40.4 & \\
\hline $5+$ & 58 & 15.9 & \\
\hline Years in marriage & & & $2 \pm 0.783$ \\
\hline
\end{tabular}




\begin{tabular}{|llll|}
\hline Variable & Frequency $(\mathbf{n})$ & Percentage (\%) & Mean \pm SD \\
\hline$<5$ & 93 & 25.4 & \\
\hline $6-10$ & 137 & 37.4 & \\
\hline$>11$ & 136 & 37.2 & $1.71 \pm 1.033$ \\
\hline Monthly income average & & & \\
\hline$<49,000$ & 219 & 59.8 & \\
\hline $50,000-99,000$ & 80 & 21.9 \\
\hline $100,000-159,000$ & 22 & 6.0 & \\
\hline$>160,000$ & 45 & 12.3 \\
\hline
\end{tabular}

\section{Prevalence of intimate partner violence among married women in Mara region}

The overall prevalence of intimate partner violence was $73.2 \%$ with $54.1 \%$ physical IPV, $25.4 \%$ sexual IPV and $36.34 \%$ psychological IPV (Fig. 1).

\section{Prevalence of modern family planning use among married women in Mara region}

The prevalence of modern FP use among married women was $62.02 \%$ (Fig. 2)

Types of modern family planning methods used among married women in Mara region

The most common family planning method used was injectable $49.1 \%$, and the least method used was male's sterilization $0.6 \%$ (Fig. 3).

\section{Reported barriers to modern family planning use among married women in Mara region}

Among the barriers of modern family planning use in this study, $57.4 \%$ was due to husband opposition followed by $41.4 \%$ resulting from fear of family planning side effects. The least barrier to using FP among the participants was cultural factors which accounted for $10 \%$ (Fig. 4).

\section{Mara region}

\section{Proportional exposed to Intimate Partner Violence by age}

Women aged 25-34 years were most affected with all the three forms of IPV (physical, sexual and psychological) at 54.9\%, $28.3 \%$ and $32.4 \%$ respectively. Those aged 45 to 49 years were less commonly abused with all three forms of IPV physical, sexual and psychological (55.6\%, 27.8\% and 27.8\% respectively) (Table 2$)$. 
Table 2

Proportional exposed to intimate partner violence by age $(n=366)$

\begin{tabular}{|lllllll|}
\hline \multirow{2}{*}{ Age category } & \multicolumn{2}{l}{ Physical violence } & \multicolumn{2}{l}{ Sexual violence } & \multicolumn{2}{l|}{ Psychological violence } \\
\cline { 2 - 7 } & No & Yes & No & Yes & No & Yes \\
& $\mathbf{n}(\%)$ & $\mathbf{n}(\%)$ & $\mathbf{n}(\%)$ & $\mathbf{n}(\%)$ & $\mathbf{n}(\%)$ & $\mathbf{n}(\%)$ \\
\hline $15-24$ & $36(42.4)$ & $49(57.7)$ & $71(83.5)$ & $14(16.5)$ & $51(60.0)$ & $34(40.0)$ \\
\hline $25-34$ & $78(45.1)$ & $95(54.9)$ & $124(71.7)$ & $49(28.3)$ & $117(67.6)$ & $56(32.4)$ \\
\hline $35-44$ & $46(51.1)$ & $44(48.9)$ & $65(72.2)$ & $25(27.8)$ & $52(57.8)$ & $38(42.2)$ \\
\hline $45-49$ & $8(44.4)$ & $10(55.6)$ & $13(72.2)$ & $5(27.8)$ & $13(72.2)$ & $5(27.8)$ \\
\hline
\end{tabular}

\section{Factors influencing modern FP use among married women in Mara region}

After adjusting for factors physical violence, psychological violence, region and availability of FP remained significantly associated with FP use. Married women who experiencing physical violence were $68 \%$ less likely to use FP compared to those who were not experiencing physical violence ( $A O R=0.32,95 \% \mathrm{Cl}: 0.29-3.82, p=0.006)$. Those who experiencing psychological violence were $78 \%$ less likely to use $\mathrm{FP}(\mathrm{AOR}=0.22,95 \% \mathrm{Cl}: 0.08-0.58, \mathrm{p}=0.002)$. Christian married women were almost 5 times more likely to use FP compared to those who were non-religious (AOR $=4.61,95 \%$ Cl: $1.48-14.41$, $p=$ 0.009). Likewise, Muslim married women were almost 3 times more likely to use FP compared to non-religious married women $(\mathrm{AOR}=2.70,95 \% \mathrm{Cl}: 0.61-12.01, \mathrm{p}<0.000)$.

Married women who agreed that FP were available were 9 more likely to use FP (AOR $=9.27,95 \%$ Cl: 7.15-84.49, $p<0.000)$. Married women who reported that FP is expensive were almost 2 times more likely not to use the FP compared to their counter parts $(A O R=1.7,95 \% \mathrm{Cl}: 0.34-8.2, p=0.525)$. Those who had fear of side effect had $55 \%$ protective effect against using FP (AOR $=0.45,95 \% \mathrm{Cl}: 0.19-1.10, p=0.088)$. Likewise, those who experiencing husband opposition in using FP were 1 time more likely not to use FP than those who did not ( $A O R=1.44,95 \% \mathrm{Cl}: 0.61-3.40, p=0.412)$. Those experiencing religious disapproval were $63 \%$ less likely to use FP compared to those who did not experiencing religious opposition (AOR $=0.37,95 \%$ Cl: 0.13-1.04, $\mathrm{p}=0.058)$ (Table 3). 
Table 3

The association between IPV, other factors and modern FP use $(\mathrm{N}=366)$

\begin{tabular}{|c|c|c|c|c|c|c|c|c|}
\hline \multirow[t]{2}{*}{ Variable } & \multirow[t]{2}{*}{ OR } & \multicolumn{2}{|l|}{$95 \% \mathrm{Cl}$} & \multirow[t]{2}{*}{$p$ value } & \multirow[t]{2}{*}{ AOR } & \multicolumn{2}{|l|}{$95 \% \mathrm{Cl}$} & \multirow[t]{2}{*}{$p$ value } \\
\hline & & Lower & Upper & & & Lower & Upper & \\
\hline \multicolumn{9}{|c|}{ Physical violence } \\
\hline No & & & & 1 & & & & \\
\hline Yes & 0.60 & 0.39 & 0.92 & 0.020 & 0.32 & 0.29 & 3.82 & 0.006 \\
\hline \multicolumn{9}{|c|}{ Sexual violence } \\
\hline No & 1 & & & & 1 & & & \\
\hline Yes & 0.67 & 0.42 & 1.08 & 0.099 & 1.18 & 0.42 & 3.30 & 0.756 \\
\hline \multicolumn{9}{|c|}{ Psychological violence } \\
\hline No & 1 & & & & 1 & & & \\
\hline Yes & 0.57 & 0.37 & 0.88 & 0.001 & 0.22 & 0.08 & 0.58 & 0.002 \\
\hline \multicolumn{9}{|l|}{ Religion } \\
\hline No religion & 1 & & & & 1 & & & \\
\hline Christian & 2.02 & 1.15 & 3.55 & 0.015 & 4.61 & 1.48 & 14.41 & 0.009 \\
\hline Muslim & 1.36 & 0.65 & 2.88 & 0.418 & 2.70 & 0.61 & 12.01 & 0.192 \\
\hline \multicolumn{9}{|c|}{ Expenses to purchase FP } \\
\hline Yes & 11.65 & 2.75 & 49.34 & 0.001 & 1.68 & 0.34 & 8.19 & 0.525 \\
\hline No & 1 & & & & 1 & & & \\
\hline \multicolumn{9}{|c|}{ Availability of FP } \\
\hline Yes & 8.50 & 5.13 & 48.63 & 0.000 & 9.27 & 7.15 & 84.49 & 0.000 \\
\hline No & 1 & & & & 1 & & & \\
\hline \multicolumn{9}{|c|}{ Pregnancy complications } \\
\hline Yes & 3.44 & 1.48 & 7.97 & 0.004 & 3.28 & 0.64 & 16.79 & 0.154 \\
\hline No & 1 & & & & 1 & & & \\
\hline \multicolumn{9}{|c|}{ Fear of FP side effects } \\
\hline Yes & 0.48 & 0.31 & 0.73 & 0.001 & 0.45 & 0.19 & 1.10 & 0.079 \\
\hline No & 1 & & & & 1 & & & \\
\hline \multicolumn{9}{|c|}{ Husband opposition } \\
\hline Yes & 0.67 & 0.44 & 1.04 & 0.073 & 1.44 & 0.61 & 3.40 & 0.412 \\
\hline No & 1 & & & & 1 & & & \\
\hline \multicolumn{9}{|c|}{ Religious disapproval } \\
\hline Yes & 0.41 & 0.24 & 0.69 & 0.001 & 0.37 & 0.13 & 1.04 & 0.058 \\
\hline
\end{tabular}




\begin{tabular}{|c|c|c|c|c|c|c|c|c|}
\hline \multirow[t]{2}{*}{ Variable } & \multirow[t]{2}{*}{ OR } & \multicolumn{2}{|l|}{$95 \% \mathrm{Cl}$} & \multirow[t]{2}{*}{$p$ value } & \multirow[t]{2}{*}{ AOR } & \multicolumn{2}{|l|}{$95 \% \mathrm{Cl}$} & \multirow[t]{2}{*}{$\mathrm{p}$ value } \\
\hline & & Lower & Upper & & & Lower & Upper & \\
\hline No & 1 & & & & 1 & & & \\
\hline
\end{tabular}

\section{Discussion}

The findings of the current study reveal the relationship between IPV and FP use among married women in Mara region. The impact of IPV on FP use has been reported to be diverse including unintended pregnancies, low use of FP methods, social effects and poor health outcomes including HIV infection $(15,16)$. Additionally, IPV has effect on physical and psychosocial health outcome (17).

In the current study, the overall prevalence of IPV among married women in the region was $73.2 \%$ with physical, psychological and sexual forms of IPV having prevalence of $54.1 \%, 36.3 \%$ and $25.4 \%$ respectively. The prevalence of IPV in the present study is higher compared to that reported in other studies such as Egypt with IPV prevalence was $29.4 \%$ with $26.7 \%$ physical, $17.8 \%$ psychological and $4.6 \%$ sexual violence (18), Nepal overall IPV psychological, physical and sexual violence was $18.3 \%, 15.2 \%$ and $2.3 \%$ respectively among married women (19). In another study conducted in six regions of Tanzania the overall IPV prevalence among married women was $65 \%$ with $34 \%$ emotional, $21 \%$ sexual and $18 \%$ physical (16).

The findings regarding the different forms of IPV in our study, their prevalence was lower as compared to that reported in Bangladesh in which the prevalence for psychological, sexual and physical forms of violence's was $77.2 \%, 58.8 \%$ and $44.4 \%$ respectively (20). These variation of findings observed in the prevalence of IPV, could be contributed by many factors, for example having outside sexual partners, alcohol use, early marriage, cohabiting, attitudes of supportive wife beating, experiencing childhood abuse, growing up with domestic violence and experiencing forms of violence in adulthood were mentioned to increase the risk of IPV practice (21). Likewise, women residing in

urban areas $(\mathrm{OR}=1.149,95 \% \mathrm{Cl}=[1.046,1.262])$, having only a primary level education $(\mathrm{OR}=1.756,95 \% \mathrm{Cl}=[1.543$, $1.999])$, being followers of Islam $(\mathrm{OR}=1.713,95 \% \mathrm{Cl}=[1.379,2.126])$, and having husbands with no education $(\mathrm{OR}=1.422$, $95 \% \mathrm{Cl}=[1.263,1.601])$ were reported factors of IPV (18).

The overall prevalence of FP use among married women in Mara region was $62.02 \%$ and its trends of modern FP use was $47.8 \%$ in 2019 and $35.5 \%$ from January to March 2020. The current result is higher compared to prevalence of FP use reported in the study conducted in Ghana 21\% (22), in 17 countries in Sub-Saharan Africa 17\% (23), in rural Northeastern Nigeria 26\% (24), in Kenya 54\% Mochache et al. (25), in Ghana and Ethiopia 34.3\%, 31.7\% respectively (26, 27) in Pakistan $34 \%$ (28). However, the current study prevalence of FP use achieved is above the national target of $60 \%$ by 2020 (13).

The prevalence of FP use in our study was low compared to reported prevalence from other studies $80.3 \%, 75 \%, 73.8 \%$ and $73.9 \%$ in United kingdom, Brazil, Uruguay and Ethiopia respectively $(1,29)$. Partner's lower level of education, preference to have children in the future, less number of live children and husband's approval were cited as reasons for not utilizing modern family planning (30). The low use of FP was also reported to be associated with discouragement from an intimate partner and closest friends (31). Another study conducted in 29 low and middle income countries reported similar finding that women's experienced IPV was associated with increased OR of having an unintended pregnancy $(95 \% \mathrm{Cl} 1.25$ to 1.34$)$ (32).

The findings in the current study revealed that commonly modern FP practiced methods among married women were injectable $49.1 \%$, implants $28.6 \%$, oral pills $24.6 \%$, other methods $16.6 \%$, male condom $6.9 \%$, IUD $6.3 \%$, female sterilization 
$3 \%$, male's sterilization $0.6 \%$ and female condom being unutilized $0.00 \%$. The probably reasons of married women preferring these methods is because have no evidence and this may be accompanied with intimate partner violence existing in male partners living in Mara region and limits married women to practice the preferred FP methods.

Our study findings are similar to the findings reported in a study conducted in Ethiopia on predictors of modern family planning use among married women and revealed that injectable $60.3 \%$ was the most common method utilized (33). However, a study done in India on family planning use among married women found that, female sterilization $45.6 \%$ was the common method utilized followed by IUD $23 \%$, condom $22 \%$ and oral pill $9.2 \%$ being the least (34). Moreover, a study done in India assessed knowledge, attitude and practice of FP methods and found that $53 \%$ of married women had used family planning methods with IUD $46 \%$ highly utilized, condom $22 \%$ and $11 \%$ oral pill accounts lowest (35). The probably reason of most married women in the current study using injectable method of FP could be associated with IPV, since this method can be used with less detection and it is given on one occasion after every three months, which could explain the confidentiality to partners (36). Likewise, low use of condom as a FP method could be due to husband disagreement and poor women autonomy in making decision regarding use of $\operatorname{FP}(22,36)$.

The findings of current study revealed that barriers of using modern family planning were fear health related side effects from using modern FP methods, husband opposition, family members opposition, cultural and religious factors. These barriers are also reported from different studies, such as Nigeria and Congo revealed that, fear of FP side effects, religious, culture, desire many children, opposition from husband and family members and expense for FP services were common barriers limiting married women to utilize modern FP methods $(37,38)$. Similarly the study conducted in Tanzania found that myths and misconceptions, fear of side effects and fear of the possibility of being pregnant during counselling period on FP use were barriers of using FP methods (31). Furthermore, a study done in Ethiopia had highlighted that, age, women' education level, power of decision making and monthly income were the positive predictors associated with modern FP use (33). These dissimilarities observed from different studies may be associated with different sociodemographic factors of the respondents for example women having good knowledge about the method of family planning was significantly associated.

We found that physical and psychological abuse were a significant factor associated with low modern FP use among married women. The reason of low utilization of FP use might be due to male dominance that husbands control their wives and don't allow their wives to use modern FP, and also, husbands might do it intentionally because they need more children. The study results is consistent with a study done in Egypt assessed the effects of married women's autonomy on utilization of modern FP methods revealed that, married women who are under the control of male partners are also limited to access modern FP (39). These findings are contrasted with a study done in England and South Asia, which reported that, there is no relationship between married women experienced IPV and modern FP use $(40,41)$. The similar findings of no association between IPV and modern FP use were also reported from a study done in Uganda (Kidman \& Bertrand, 2015; Wandera, et al, 2018). This findings are contracted with a study done in Tanzania to determine factors influencing modern family planning use among women of reproductive age revealed that, women who made their own decision were more likely to practice FP methods than those who are not (32; Martin et al., 2019). However, a study conducted by Sebert, Shato, and Sierra (2019) (42) in Hondras explored the relationship between (IPV), pregnancy intention and FP use. The findings argued that there is no statistical association between intimate partner violence on modern FP use among married women.

The Christian married women were independent factor for practicing modern family planning methods than those the counterparts. This result is in line with Patton and Dalton (2015) conducted a study in United State of America, in Nigeria (44) in Rwanda and France assessed the relationship between sociodemographic factors and FP use. The results in current study was inconsistently that respondents who practice religious were less likely to utilize FP methods (45). The probable reason of Christian religious being more likely to use FP methods could be the civilization of the importance of child spacing (46). Likewise, it has been reported by the leaders of Roman Catholic church that Catholics do not have to breed like a rabbits, however they are allowed to use temporal family planning methods and prohibited from using emergency 
contraception and abortion without exception, even in life threatening of the a pregnant woman (47). Additionally, Protestantism have been reported to be flexible in using family planning for the sake of family size and the type of contraceptive use (47).

The findings of the current study showed that, respondents were more likely to utilize modern family planning methods if the preferred FP methods are available in health facilities compared to those respondents who were not able to access the methods. Similar results were reported in the studies done Ethiopia, Zambia and Burundi $(48,49,50)$.

\section{Conclusion And Recommendations}

All forms of violence showed significance reduction in the use of modern family planning method, efforts to increase the use of modern FP should be integrated with women rights and abused women.

\section{Abbreviations}

DHIS

Demographic Health Survey

FP

Family planning

IUD

Intrauterine device

NBS

National Bureau of statistics

UN

United Nations

\section{Declarations}

\section{Ethics approval}

Ethical clearance was obtained from the Institutional Review Board of the University of Dodoma. Ethical issues were highly observed so as to ensure the researcher followed the human rights and country policies. Permission to conduct the study was obtained from Mara region and respectively districts administrative authorities.

\section{Consent to participate for publication}

All the participants signed a written consent for their participation and publication in the study.

\section{Availability of data and materials}

Data will be available on request

\section{Competing interests}

The authors have no conflict of interest to declare.

\section{Funding}

No funding was received.

\section{Authors' contributions}


MSB contributed to the conception, design and conduct of the study, analysis and interpreted the data, and prepared the manuscript. AAJ contributed to the conception, design and conduct of the study, analysed and interpreted the data, and prepared the manuscript. All authors read and approved the final manuscript.

\section{References}

1. United Nations, Department of Economic and Social Affairs, Population Division. (2017). Reproductive Health Policies 2017: Data Booklet (ST/ESA/

SER.A/396).https://www.un.org/en/development/desa/population/publications/pdf/policy/reproductive_health_polici. 2017.

2. Moller A, Petzold M, Chou D, Say L. Patterns and causes of hospital maternal mortality in Tanzania: A 10-year retrospective analysis. Lancet Glob Heal. 2019;5(10):e977-83.

3. National Bureau Statistics. Tanzania Demographic and Health Survey and Malaria Indicator Survey 2015-2016. Dar es Salaam; 2016.

4. Bwana VM, Rumisha SF, Mremi IR, Lyimo EP, Mboera LE. (2019). Patterns and causes of hospital maternal mortality in Tanzania: A 10-year retrospective analysis. 2019;24(2006):1-22.

5. Ajayi Al, Adeniyi OV, Akpan W. Use of traditional and modern contraceptives among childbearing women: findings from a mixed methods study in two southwestern Nigerian states. 2018;1-9.

6. Kavana NJ, Issa IM. Assessment of Awareness and Practice of Modern Contraceptive Use among Women Attending Antenatal Clinic in Morogoro Municipality, Tanzania. Gynaecology and Perinatology 2.4 (2018): 314-321. 2018;2(4):314-21.

7. Kidayi PL, Msuya S, Todd J, Mtuya CC, Mtuy T, Mahande MJ. Determinants of Modern Contraceptive Use among Women of Reproductive Age in Tanzania: Evidence from Tanzania Demographic and Health Survey Data. 2015;(July).

8. Reyna S, Mart H, Chico-barba G, Bernarda S, Sam-soto S, Lilia A, et al. Sociodemographic Factors Associated with the Knowledge and Use of Birth Control Methods in Adolescents before and after Pregnancy. 2019.

9. Temmerman PM. Patterns of Contraceptive Use among Vulnerable Populations in Kenya. Director, Centre of Excellence Women and Child Health, Aga Khan University, Kenya: 2017.

10. Sunnu E, Adatara P, Opare FY, Kuug A, Nyande F. Factors Influencing the Utilisation of Family Planning contraceptives among Men and Women in the Ho Municipality of Ghana. 2016;6(August):204-13.

11. Hossain MB, Khan MHR. Identifying factors influencing contraceptive use in Bangladesh: evidence from BDHS 2014 data. 2018;1-14.

12. Wandera SO, Kwagala B. \& Odimegwu C. among married women in Uganda: a cross-sectional study. 2018;8688:1-11.

13. National Bureau of Statistics. Tanzania Demographic and Health Survey and Malaria Indicator Survey (TDHS-MIS) 2015-16. 2016. p. 172-3.

14. Straus, et al. J Fam Issues. 1996;17(May):283-316.

15. Abdul-Khabir W, Hall T, Swanson AN, Shoptaw S. Intimate Partner Violence and Reproductive Health Among Methamphetamine-Using Women in Los Angeles: A Qualitative Pilot Study. J Psychoactive Drugs. 2014;46(4):310-6.

16. Kazaura MR, Ezekiel MJ, Chitama D. Magnitude and factors associated with intimate partner violence in mainland Tanzania. BMC Public Health. 2016;1-7.

17. Emenike E, Lawoko S, Dalal K. Intimate partner violence and reproductive health of women in Kenya. Int Nurs Rev. 2008;55(1):97-102.

18. Yaya S, Hudani A, Buh A, Bishwajit G. Prevalence and Predictors of Intimate Partner Violence Among Married Women in Egypt. J Interpers Violence. 2019;1-19. 
19. Sapkota D, Bhattarai S, Baral D, Pokharel PK. Domestic violence and its associated factors among married women of a village development committee of rural Nepal. BMC Res Notes. 2016;1-9.

20. Esie P, Osypuk TL, Schuler SR, Bates LM. SSM - Population Health Intimate partner violence and depression in rural Bangladesh: Accounting for violence severity in a high prevalence setting. SSM - Popul Heal. 2019;7(August 2018):100368.

21. Abramsky T, Watts $\mathrm{CH}$, Garcia-moreno $\mathrm{C}$, Devries $\mathrm{K}$, Kiss L, Ellsberg $\mathrm{M}$, et al. What factors are associated with recent intimate partner violence ? findings from the WHO multi-country study on women 's health and domestic violence. BMC Public Health. 2011.

22. Beson P, Appiah R, Adomah-afari A. Modern contraceptive use among reproductive-aged women in Ghana: prevalence, predictors, and policy implications. 2018;1-8.

23. Ba DM, Ssentongo P, Agbese E, Kjerulff KH. Prevalence and predictors of contraceptive use among women of reproductive age in 17 sub-Saharan African countries: A large population-based study. Sex Reprod Healthc. 2019;21(May):26-32.

24. Kana M, Tagurum Y, Hassan Z, Afolanranmi T, Ogbeyi G, Difa J, et al. Prevalence and determinants of contraceptive use in rural Northeastern Nigeria: Results of a mixed qualitative and quantitative assessment. Ann Niger Med. 2016;10(1):3.

25. Mochache V, Lakhani A, El-busaidy H, Temmerman M, Gichangi P. Pattern and determinants of contraceptive usage among women of reproductive age from the Digo community residing in Kwale, Kenya : results from a cross-sectional household survey. 2018;1-11.

26. Abdulai M. Factors influencing contraceptive uptake among reproductive women in tamale metropolis. University of Ghana http://ugspace.ug.edu.gh. (10239012). (10239012). 2015;(10239012).

27. Debebe S, Limenih MA, Biadgo B. Modern contraceptive methods utilization and associated factors among reproductive aged women in rural Dembia District, northwest Ethiopia: Community based cross-sectional study. 2017;15(6):367-74.

28. Noreen K, Khalid N. Contraceptive prevalence rate, unmet need for family planning and its associated factors among women of reproductive age group. 2018;8(2):2-8.

29. Girma T, Sultan A, Legese K. Prevalence and Factors Influences Utilization of Modern Contraceptive Methods among Married Women of Reproductive Age Group (15-49 Years) in Journal of Pregnancy and Child Prevalence and Factors Influences Utilization of Modern Contraceptive Methods amo. 2016;(September).

30. Alamdo AG, Debere MK, Tirfe ZM. Factors associated with non-utilization of long acting and permanent contraceptive methods among married women of reproductive age in Chencha district. Southern Ethiopia: a case-control study; 2020.

31. Mushy SE, Tarimo EAM, Fredrick Massae A, Horiuchi S. Barriers to the uptake of modern family planning methods among female youth of Temeke District in Dar es Salaam, Tanzania: A qualitative study. Sex Reprod Healthc [Internet]. 2020;24(June 2019):100499. Available from: https://doi.org/10.1016/j.srhc.2020.100499.

32. Maxwell L, Nandi A, Benedetti A, Devries K, Wagman J, García-Moreno C. Intimate partner violence and pregnancy spacing: Results from a meta-analysis of individual participant time-to-event data from 29 low-and-middle-income countries. BMJ Glob Heal. 2018;3(1).

33. Tekelab T, Melka AS, Wirtu D. Predictors of modern contraceptive methods use among married women of reproductive age groups in Western Ethiopia: a community based cross-sectional study. BMC Womens Health. 2015;1-8.

34. Gupta V, Mohapatra D, Kumar V. Family planning knowledge, attitude, and practices among the currently married women (aged 15-45 years) in an urban area of Rohtak district, Haryana. 2016;5(04).

35. Quereish MJ, Mathew AK, Sinha A Knowledge, attitude and practice of family planning methods among the rural females of Bagbahara block Mahasamund district in Chhattishgarh State, India. 2017. 
36. Tomar S, Dehingia N, Dey AK, Chandurkar D, Raj A, Silverman JG. Associations of intimate partner violence and reproductive coercion with contraceptive use in Uttar Pradesh, India: How associations differ across contraceptive methods. PLoS One. 2020;15(10 October):1-12.

37. Muanda M, Ndongo PG, Taub LD, Bertrand JT. Barriers to Modern Contraceptive Use in Kinshasa, DRC. 2016;1-13.

38. Mafuyai MJ, Emmanuel E, Solomon G, Barry A, Abadiah A. Perception practice of family planning among rural women in North Central Nigeria. 2014;8(1):14-9.

39. Alsumri HH. Review of Quality of Care A National Study: the Effect of Egyptian Married Women 's Decision-Making Autonomy on the use of Modern. Family Planning Methods. 2015;19(December):68-77.

40. Raj A. \&, McDougal L. Associations of intimate partner violence with unintended pregnancy and pre-pregnancy contraceptive use in South Asia. 2015.

41. Lewis NV, Moore TH, Feder GS, Macleod J, Whiting P. (2018). Use of emergency contraception among women with experience of domestic violence and abuse: a systematic review. 2018.

42. Sebert A, Shato T, Fu Q, Sierra M. Intimate partner violence, pregnancy intention and contraceptive use in Honduras. Contraception. 2019;100(2):137-41.

43. Patton EW, Stidham K, Dalton VK. How does religious affiliation affect women 's attitudes toward reproductive health policy ? Implications for the Affordable. Contraception. 2015;91(6):513-9.

44. Adedin SA, Akiode A. Role of religious leaders in promoting contraceptive use in Nigeria: evidence from the Nigerian Urban Reproductive Health Initiative. Glob Health Sci Pract. 2018;6(3):500-514. https://doi.org/10.9745/. 2018;50014.

45. Moreau C, Trussell J, Bajos N. and patterns of sexual activity and contraceptive use in France. 2013;168-80.

46. Sundararajan R, Yoder LM, Kihunrwa A, Aristide C, Kalluvya SE, Downs DJ, et al. How gender and religion impact uptake of family planning: Results from a qualitative study in Northwestern Tanzania. BMC Womens Health. 2019;19(1):1-10.

47. Pinter B, Hakim M, Seidman DS, Kubba A, Kishen M, Di Carlo C. Religion and family planning. Eur J Contracept Reprod Heal Care [Internet]. 2016;21(6):486-95. Available from: http://dx.doi.org/10.1080/13625187.2016.1237631.

48. Shiferaw S, Spigt M, Seme A, Amogne A, Skr S, Desta S, et al. Does proximity of women to facilities with better choice of contraceptives affect their contraceptive utilization in rural Ethiopia ? 2017.

49. Chanda MM, Ortblad KF, Mwale M, Chongo S, Kanchele C, Kamungoma N, et al. Contraceptive use and unplanned pregnancy among female sex workers in Zambia. Contraception. 2017.

50. Ndayizigiye M, Fawzi MCS, Lively CT, Ware NC. Understanding low uptake of contraceptives in resource-limited settings: a mixed-methods study in rural Burundi. 2017;1-12.

\section{Figures}






\section{Figure 1}

Prevalence of intimate partner violence among married women in Mara region

$$
\begin{aligned}
& 70
\end{aligned}
$$

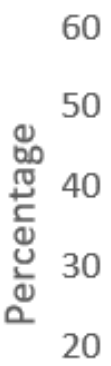

$$
\begin{aligned}
& 10
\end{aligned}
$$

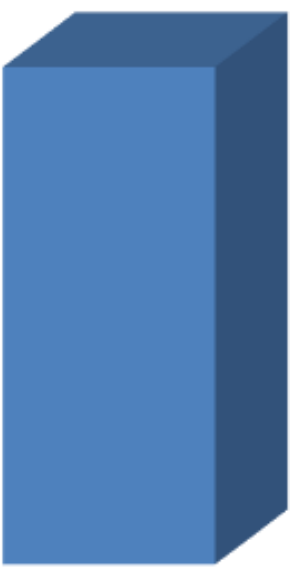

users

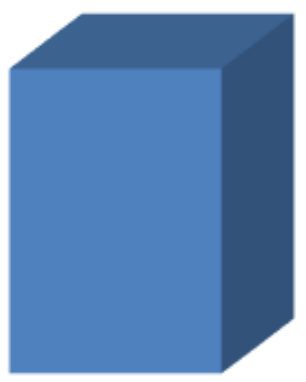

Non users

Pamily planning

\section{Figure 2}

Prevalence of modern FP use among married women in Mara region 


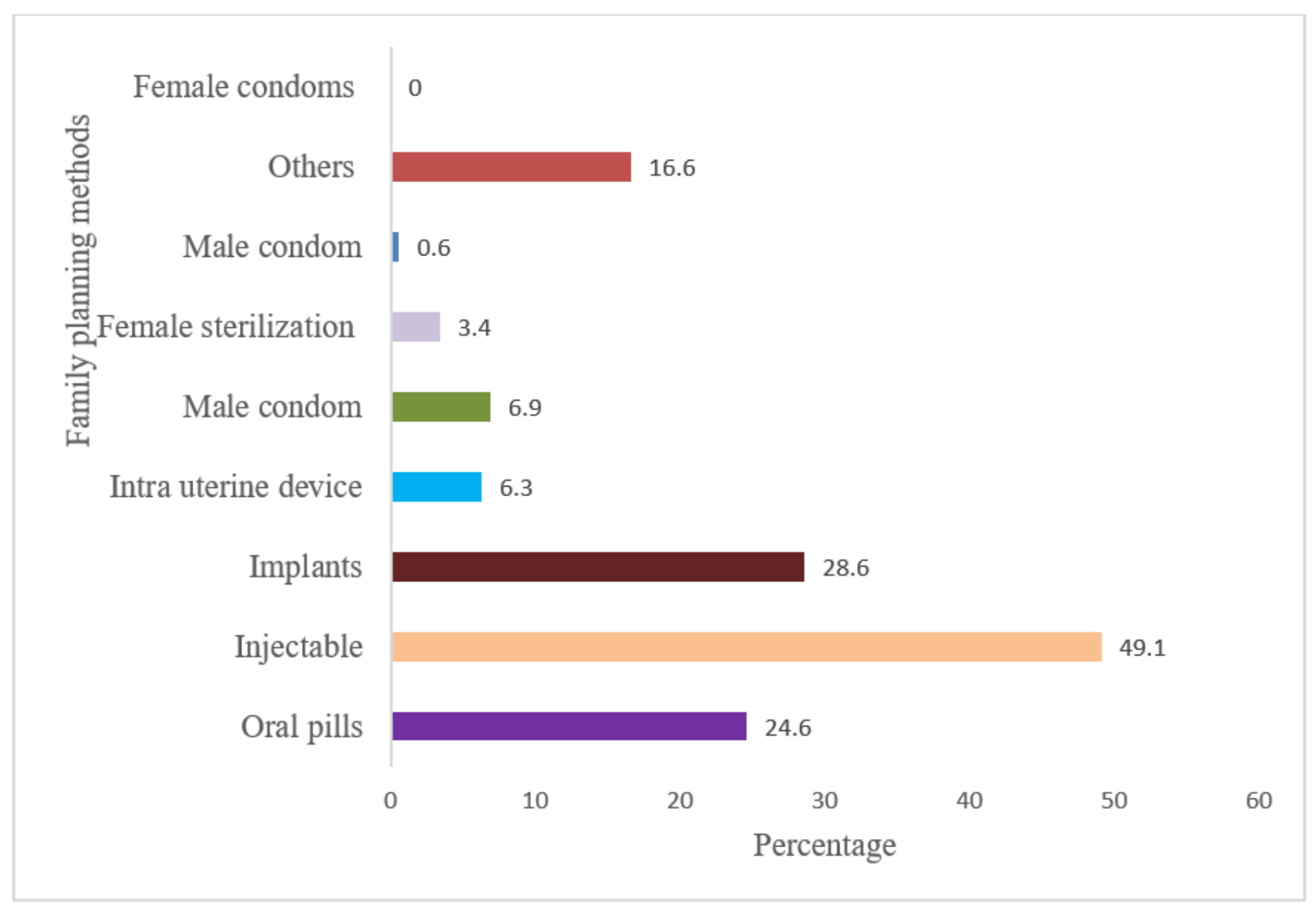

Figure 3

Types of modern FP methods used among married women in Mara region Reported barriers to modern family planning use among married women in Mara region 




Figure 4

Reported barriers to modern FP use among married women in Mara region 